\title{
Meditation on medical practice
}

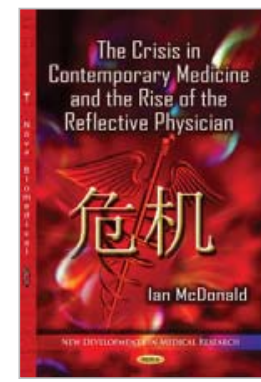

The crisis in contemporary medicine and the rise of the reflective physician. New developments in medical research: public health in the 21st century series. Ian McDonald. Hauppauge, New York: Nova Science Publishers, 2013 (e-book, US\$195.00). ISBN 978162618464.

IAN MCDONALD, in his life as a leading cardiologist in a pre-eminent teaching hospital whose values statement is carved in granite in the foyer, embodies the reflective physician. His book reflects his lifelong quest to reconcile the two increasingly irreconcilable and disparate objectives of the hospital and the university in the person of the doctor as lifelong learner. He sees that individuals must take control of their learning in order to become better doctors with a better understanding of their role in a complex and ever-changing world.

McDonald prescribes - good doctor that he is - a remedy for both the individual learner and the organisation: an institute of reflective practice, where education is built into professional practice, and practice into education. His call is also for the construction and maintenance of a social good and an explicit statement of purpose and values in health care, supported by the institutions and professional community, to avoid the operational objectives ruckus of key performance indicators subsuming them.

His book divides his career into 20-year epochs with an intervening transition. The first epoch is a biomedical golden age of medical dominance and professional self-regulation reflecting the public's trust. The transition zone was/is marked by changing social conventions and expectations and public dissatisfaction with a medical-centric model of care. The second epoch heralds a new postmodern paradigm in which qualitative and interpretative thinking from the social sciences informs medical care.

Early chapters cover controversies within medicine, the incorporation of science within the dominant medical paradigm and the recognition of a broader societal and hence political environment surrounding it. Alternative medicine, clinical inefficiency, failure of consultation (its symptoms and consequences) and evidence-based medicine (seen as having become antithetical and authoritarian) are discussed. Finally, the role of medicine within our society arrives and is redeemed with the creation of a Centre for the Study of Clinical Practice, where art and science are enriched by Aristotelian rhetoric and debate. This enables the reflective practitioner to create health care fit for purpose in the postmodern era.

This book breaks new ground. Will it find an audience? Yes. The book brings together the author's great love for the conversation between clinical medicine and the humanities to ensure clinical medicine's continuing relevance.

McDonald is a patient guide and has dealt with his subject with great discipline and mastery. I commend it to clinicians, health service CEOs, deans of medical faculties and politicians but, above all, to all students who continue to wonder at and seek to better understand clinical practice.

Donald Campbell Medical Director General Medicine

Monash Health, Melbourne, VIC. doi: 10.5694/mjal4.01024 